IP Periodica Polytechnica

Transportation Engineering

44(4), pp. 209-214, 2016

DOI: $10.3311 /$ PPtr. 8446

Creative Commons Attribution (i)

\title{
Using Qualitative Study and GIS to Explore Road Accident Black Areas in Algeria
}

\author{
Ramtane Oulha ${ }^{1,2}$, Ahmed Boumediene ${ }^{1}$, Khaled Amara ${ }^{3 *}$, Samir \\ Benyoucef $^{3}$, Mohamed Amine Hamadouche ${ }^{2}$, Kouider Brahimi ${ }^{1}$
}

RESEARCH ARTICLE

Received 29 July 2015; accepted 08 February 2016

\begin{abstract}
This work aims to explore black areas identification through a qualitative methodology based mainly on a series of questionnaires and interviews and by a development of a geographical information system on the road accidents in studied area. The road user, particularly the driver, is generally considered as the first person in charge in the case of accident, while his opinion is rarely joined into the establishment of the solutions to the problems of the road insecurity. Considering needs for the treatment of black areas, problems of the lack of data on the accidents, the different advantages that suggests the concept of participation and the feasibility integrating the road users into the analysis of the road safety. The Qualitative study aims at supplying with the accessibility for the users of the road to indicate the places of male performances of safety according to their feeling and of them the experience. The approach by the GIS aims at first to establish road accidents on the studied site by associating data of different nature and then to make a spatial analysis via ArcGis tool. The study area is a section of national road Highway RN6 of $38 \mathrm{Kms}$ (from the PKO0 to the PK38) which across the wilaya of Mascara. it is considered a potentially dangerous stretch in terms of road insafety. The results of this study show that the road users are the daily witnesses on the degree of the danger which presents their usual territory: the road. They can, therefore, to be the complementary information source for the localization of zones at high risk on the road network traveled daily.
\end{abstract}

\section{Keywords}

road safety, black areas location, Geographical Information System, road user's participation

\footnotetext{
${ }^{1}$ Department of Civil Engineering, University of USTO-MB, El Mnaouar, BP 1505, Bir El Djir 31000, Oran, Algeria

${ }^{2}$ University of Mascara, BP 305, Route de Mamounia, 29000 Mascara, Algeria

${ }^{3}$ Laboratory of Materials and Hydrology, Sidi Bel Abbes 22000, Algeria

*Corresponding author, e-mail: amara3176@yahoo.fr
}

\section{Introduction}

Traffic safety is very important question. Lots have been researched (Levulyté et al., 2016; Torok, 2015). The problems posed by the road traffic, in Algeria, became at the moment a severe subject of concern. According to the National Center of Prevention and Road safety (CNPSR, 2012), 4531 persons killed and 64936 persons injured and more than 42023 accidents were registered on 2011. Indeed, one account 12 deaths, 120 persons injured and 115 crash a day. This denotes the extreme revolved by such a plague and proves that the Algerian roads are of the most murderous. Every year the road accidents cause more than 4000 handicapped persons (association of the handicapped persons, the reference). The road accidents cost more than 100 million dollars a year for the treasury. According to the Ministry of Transport, that is approximately $2 \%$ of the GDP of the country (Chanut, 2011).

The road accidents represent approximately $70 \%$ of the accidents in rural zone and approximately $56 \%$ of accidents on all national road networks in 2011 (Subba Rao et al., 2010). The Main roads which register (record) more traffic accidents are: RN6 (Bechar-Mascara), RN5 (Algiers-Constantine), RN1 (Algiers-Djelfa), RN4 (Algiers-Mascara-Oran), RN3 (SkikdaConstantine), RN11 (Algiers-Mostaganem), with respectively $24 \%, 20 \%, 19 \%, 13 \%, 13 \%$ and $10 \%$ of accident.

Wilaya of Mascara occupies a strategic geographical position, making the wilaya a crossroads of all Western Algerian towards all regions (West, East, North, and South). It is characterized by a dense network highway, composed of twelve sections, with a very high mobility of people and goods (Oulha et al., 2013). The most important axes that cross the province are stretch N4, N6, RN14, N7, RN17 and RN17A, respectively connecting the wilaya of Mascara with wilayates Oran, Relizane, Saida, Tiaret, Sidi Bel Abbes (Fig. 1).

The wilaya of Mascara is one of the most affected Algerian wilaya by road accidents especially in rural areas. It is ranked second among rural and 6th at the national level according to the number of fatalities of road accidents in 2008. The accidents on highways in Mascara represent about $70 \%$ of accidents in rural areas and about $56 \%$ of all accidents on the road network of the wilaya in 2010. 
In 2009, the services of the National Gendarmerie reported 64 killed due to road accidents in the stretch between RN6 Mascara and Oran which represents about $40 \%$ of all accidents killed at the scale of the wilaya (Subba et al., 2010).

\section{Presentation of the study area}

Algeria has begun, following the crisis caused by falling oil prices in 1986, structural reforms which were aimed at abandoning the system of economic management and social, highly centralized, for a system of market economy, liberal oriented. The study site is a section of national road N6 Sig linking the city to the north and the town of Mascara south of $38 \mathrm{Kms}$ in length (the Sig PK0.00 to KP 38) Fig. 1. This section is of vital importance, not only for the province of Mascara but also to several provinces of Algeria Adrar it connects the South and the North Oran. An important vehicle traffic runs daily on this route. This traffic consists of all types of vehicles with a strong presence of heavy trucks (Oulha et al., 2013).

It is a winding stretch with several slopes of $10 \%$, plus the fact that it supports heavy traffic at all times and in all categories of vehicles. The morphology of this section requires heavy practicing at low speeds on a dual carriageway direction not exceeding 6 meters in width see Table 1, which causes discomfort to the flow of traffic for light vehicles, leading to dangerous maneuvers where many of them end badly. The geographical position occupied Mascara and making it an area of transition from a large flow of lorries on Oran axes - Mascara Adrar (N6), consisting essentially of buses carrying passengers and tankers carrying fuel.

Under this study, we used the network mainly in the wilaya of Mascara and the axis of the N6 on the territories of the province of Mascara and Saida. This choice is justified by several factors:

- Dense network used by local traffic and transit traffic (north-south and east-west) important because it acts as an interface between the north west and south west and the High Plateau in the west,

- Different types and sizes vehicles using the network,

- Network rural primary component that concentrates the majority of accidents ( $56 \%$ against a national average of $88 \%$ for Mascara),

- Mascara is ranked 2nd (in 2008) at the national level for accidents in rural areas,

- Diversification geometric layout and environment,

- Proximity to the different actors in the acquisition of information.

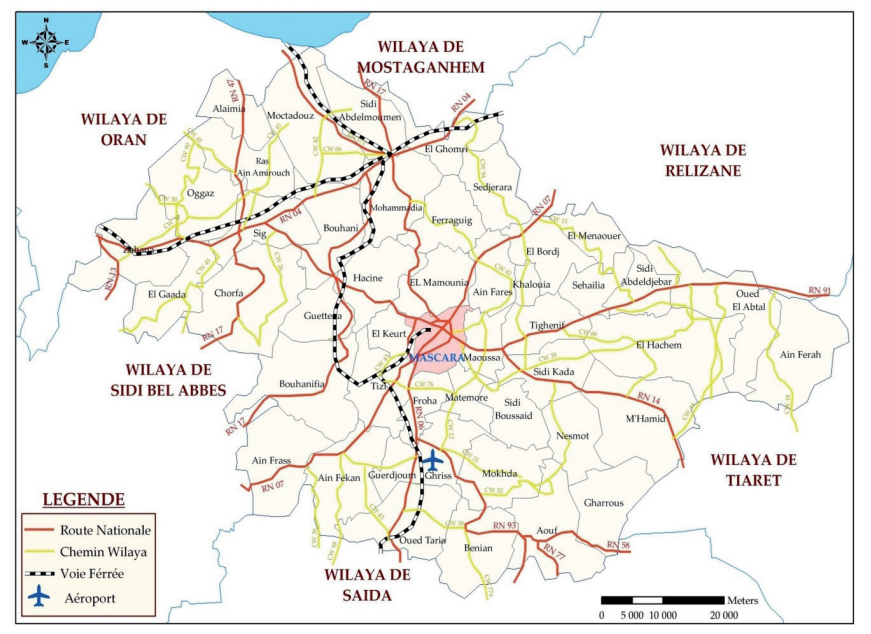

Fig. 1 RN6 and road network in the wilaya of Mascara, source: DPAT Mascara, 2010

The Figure 1 shows that the wilaya of Mascara is characterized by dense network roads. One of the most important in areas of the province is the section of RN6 between Saida and Sig.

\section{Methods}

The Objective of this work is to try to approach drivers (taxis inter-wilaya, buses, trucks, vans, private) as daily users of the axis N6 and daily witnesses at risk in order to locate the best places dangerous than present this axis. Risk factors are very crucial in road safety assessment (Çelik and Senger, 2014).

The approach followed in the analysis of road accidents on the stretch of N6 kilometer point (KP) PK No. 00 to No. 38 PK is to use two sources of information on the location of road accidents: accident statistics road mileage by point provided by the services of the National Gendarmerie over a period of five years (2005 to 2009), interviews and questionnaires of different drivers on this stretch more often (bus drivers, trucks and taxieurs inter wilaya (Mascara - Oran - Mascara.) This survey was carried out during the months of February and March 2012.

The methodology used in this paper is to make the diagnosis in the field, to identify high-risk areas and to propose feasible solutions to improve road safety. The diagnosis was made in three stages:

1. Video making the entire section of the N6 and pictures of each kilometer point: the aim of the video is taken to question the drivers using this tool to determine the nature of the risk and identify anomalies observed. And examine the shortcomings of the development course of the road.

2. Collection of statistics of accidents at the national gendarmerie: The stage that followed the diagnosis in the field, it is the collection of statistics on road accidents per kilometer point. The goal is to do a preliminary analysis of road risk before establishing the first accident map of this stretch.

3. Displacement in vehicles of drivers surveyed: We conducted 30 trips in vehicles of drivers surveyed (15 taxi 
vehicles, 5 buses, 5 cars and 5 heavy trucks) while questioning drivers about the dangers they face on this stretch. Of these 30 trips, 13 trips were made in direction (PK38 to PK00) and 17 travel in the direction (PK00 to PK) 38 to see the reviews on road risks in both directions. This method has allowed us to understand more risk situations and address the specific abnormalities every kilometer points.

Use of GIS for digitizing the road network: This step is important because it allows for modeling the RN6 section in order to conduct various manipulations and analyzes.

\section{Collecting information}

The collection of information necessary for the preparation of this work was performed at the following organizations:

- National Gendarmerie (accidents per kilometer point from 2005 to 2009);

- The Directorate of Public Works (geometric characteristics of the section of the road, work on the floor, etc.).

- The Department of Transportation (various statistics of accidents in urban and rural areas);

- The Union taxieurs (number of taxieurs on line Mascara - Oran);

- The company Algerian Des Eaux (ADE) (for number of drivers on the stretch Mascara - Sig).

\section{Presentation of the sample interviews and questionnaire (survey)}

A sample of 144 drivers has been developed. This sample is composed of several drivers of different vehicles: taxi drivers inter wilaya of heavy trucks, vans carrying goods, buses and private drivers. The goal is to have a representative sample of the population of drivers on the stretch N6. The sample was allocated as follows:

- 35 drivers inter-wilaya taxi;

- 20 drivers of trucks;

- 20 company drivers ADE: Algerian Des Eaux;

- 10 truck drivers;

- 20 bus drivers;

- 39 individual drivers (academics, students, traders, etc.).

The questionnaire consists of two sections, the first is used to identify the respondent and the second includes questions about the location of places that have a high risk road, the feeling of insecurity in driving the section on evidence of accidents and damage reported by drivers and weather conditions at the time of the accident. The responses are then coded and analyzed by SPSS software.

In addition, thirty interviews were conducted with taxi drivers inter wilaya (Sig-Mascara-Mascara-Oran) and bus transit in the same line. These interviews were conducted in their vehicles while traveling with these drivers. The objective was to locate the most accident-prone locations, abnormal road layout and amenities that may be introduced on the road environment, according to these drivers, to improve the driving safety. The information collected during interviews complement those of the questionnaire. A GIS has been developed in stages are summarized in Fig. 2; to locate places high road risk is to treat the black points.

\section{Spatial Analysis of road risk}

Many studies have been conducted to explore road accident black areas using GIS (Thériault, 1996; Austina et al., 1997; Anderson, 2007; Savena, 2011).

Spatial analysis is the most powerful and richest mode. It consists in the analysis capabilities of operators to incorporate in queries geometric criteria and some opportunities calculations on geographic data. The different relationships that can be implemented concern the nearby (find objects close to one another), topology (joined objects included, partially included, excluded ... etc.) or shape. It is possible to combine the geometric properties with semantic properties to achieve a fairly complete analysis. Other spatial analysis functions are mathematical operations that exploit the topological properties of spatial data:

- Creating buffers around points, lines, areas, polygons ;

- Crossing polygons (polygons calculation resulting from the intersection of two or more surface objects) and more generally Boolean operations on polygons (intersection, union, inclusion, exclusion ... etc.).

- Analysis graphs (search the shortest path following distance or some other criterion.)

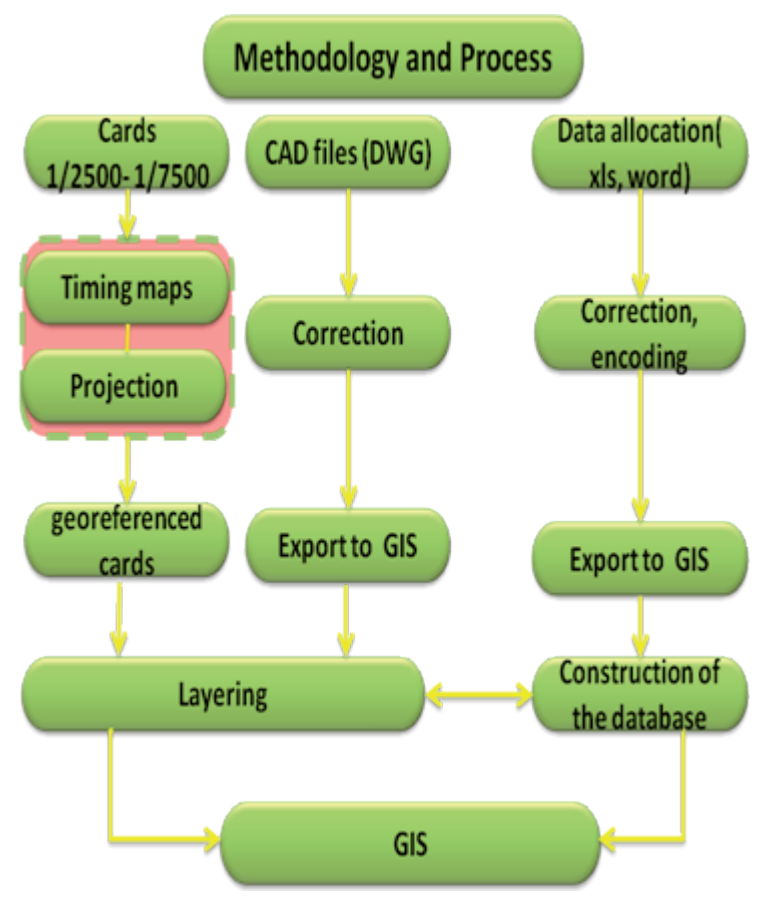

Fig. 2 Steps acquisition and transmission of information 


\section{Results and discussion}

Following the question: "in general, is that you feel safe in using the road", the responses of drivers are shown in Fig. 3 and Fig. 4.

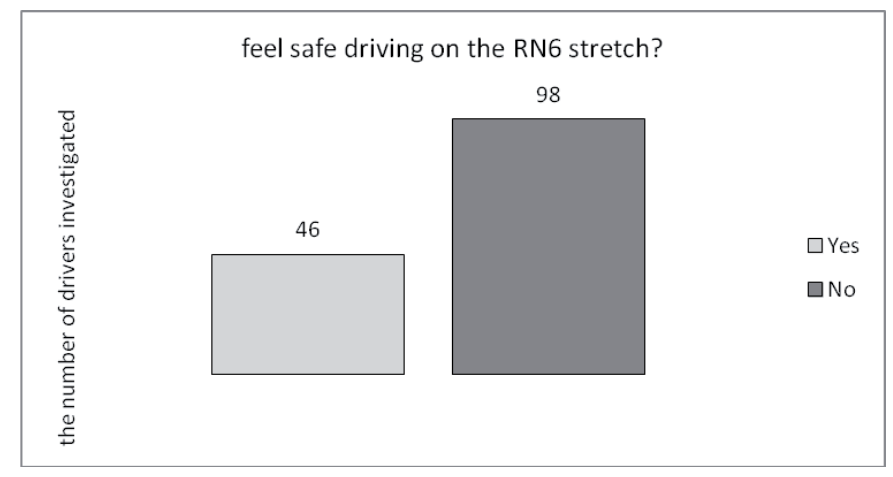

Fig. 3 Feeling of security / insecurity on the section of RN6

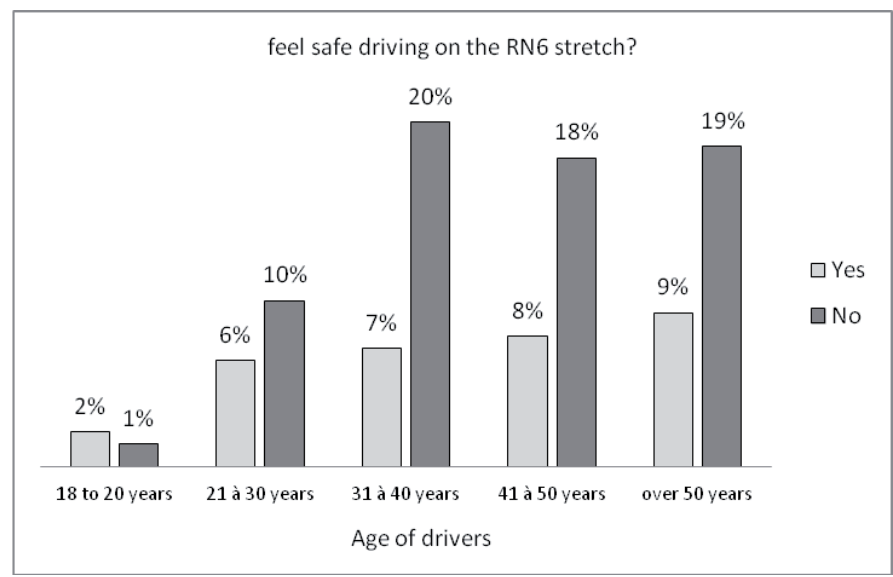

Fig. 4 Feeling of safety on the RN6 stretch depending on the age of the driver

From the figure we see, $68 \%$ of users admit that the section (Mascara-Oran) is dangerous (Yes: $31.9 \%$ and No: 68.1\%).

From Figure 4, the drivers who are age over 30 years feel more unsafe driving on the stretch N6 (that is to say, they said no security) compared those with age less than 30 years.

Zhao et al. (2015) noticed that for Xi' an city the taxi drivers with 3 to 5 years experience are at greater risk for crashes than other groups. The results of the present study corroborate with those found in Xi'an city.

Figure 5 shows that drivers who are driving age less than 15 years on the section N6 feel insecure driving on the stretch N6 (that is to say, they said no) with a percentage important. By against drivers who have seniority driving more than 16 years on the stretch N6 (old drivers) feel more safety while driving on this stretch (Zhao et al., 2011).

In the opinion of users asked about the main causes of accidents on the section studied, approximately $35 \%$ of accidents are due to the lack of visibility in the N6 stretch, $25 \%$ are due to driving errors (excessive speed, dangerous overspending, lack of concentration for drivers) and over $10 \%$ are due to the poor road design, and the presence of mixed traffic on the road (trucks, individuals vehicles, motorized two-wheelers, etc). (Lam, 2004; Mitsakis, 2015) concluded that professional taxi or bus or lorry drivers are at a greater risk of being involved in a vehicle crash, due to their occupational exposure to hazardous fatigue and stress.

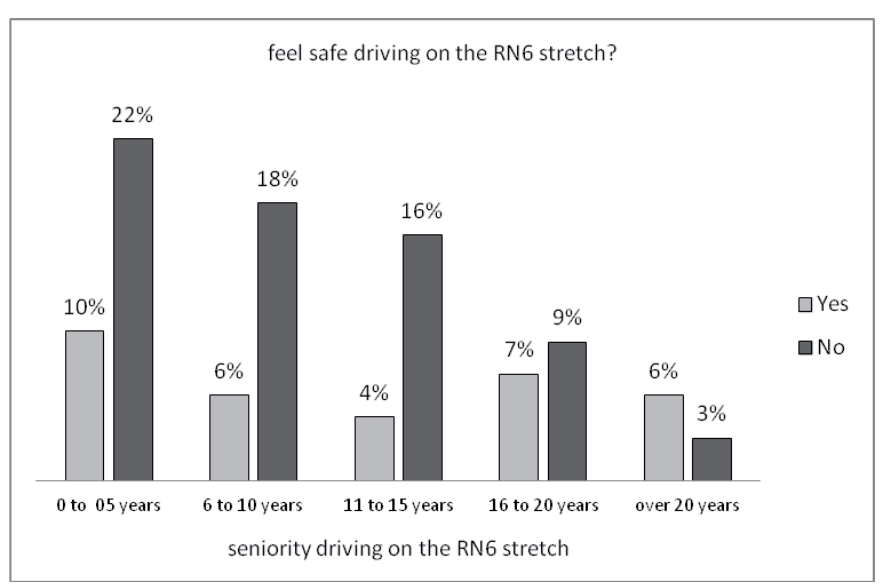

Fig. 5 Safety feeling depending on the seniority driving

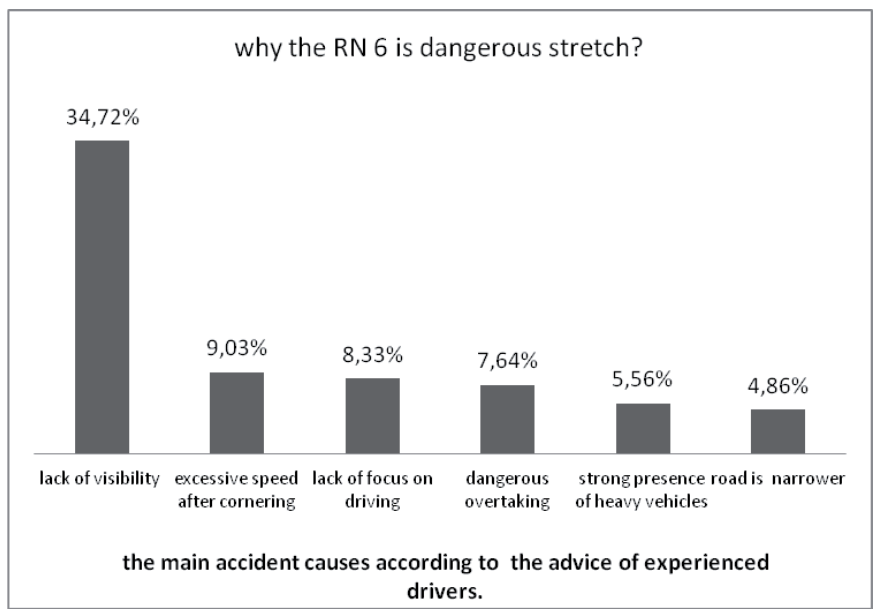

Fig. 6 The views of users on the causes of accidents

The existence of the corners is both a positive and negative in the occurrence of the accident factor. Indeed, the existence of corners makes the driver more careful when driving and thus flows at moderate speeds. Even if there would be accidents, they will not usually fatal (CNPSR, 2012; Oulha, 2004). By cons, straight roads can generate monotony when driving, especially when it comes to long distances, and drivers feel more confident and well practiced excessive speeds which leads in most cases to unpredictable accidents and fatal.

On the other hand, the section is full of turns with the existence of vehicles at various speeds (PL, goods vehicles, V Light) causing traffic jams. Thus, out of the corners, drivers tend to recover delay dangerous maneuvers (dangerous overtaking, excessive speed, failure to respect the rules of the roads). 
Table 1 Damage reported by drivers

\begin{tabular}{lll}
\hline Damage reported by drivers & Number of drivers & \\
\hline damage, deaths and injuries & 27 & 18.8 \\
damage & 24 & 16.7 \\
damage and killed & 26 & 18.1 \\
damage and injuries & 29 & 20.1 \\
no findings & 38 & 26.4 \\
Total & 144 & 100.0 \\
\hline
\end{tabular}

$27 \%$ confirm that they have witnessed accidents that caused property damage and killed and/or injured. Certainly, it should be noted that the judgment of drivers remain subject because the state of a victim of a traffic accident can be defined as a specialist in the field (Cloutier et al., 2011; Duffey et al., 2003). But these opinions are the stretch as deadly (CNPSR, 2012; Henri, 1995).

According to the observation of users, the majority of accidents resulting in casualties (deaths and injuries) on the N6 occurred either during times of rain, sleet or fog. But this does not exclude that during other times it is not no accidents or victims, and the findings also show that no matter how long this section records of accidents and victims. Unanimously, all users, regardless of their ages are, seniority and levels of education, noted the danger of the section of the RN6 OranMascara, and the majority said they witnessed an accident. The age of the user has an important role in mastering the handling of the vehicle, the anticipation of potential accidents. Also, seniority in the conduct of the same section allows the user to have a normal reflex of errors likely to cause reactions incidents (Joerin, 1997; Thériault, 1996).

Counts carried out on the site have shown that there is a complexity of traffic over the N4 and N6 (Fig. 7). The agricultural character of the Wilaya of Mascara has found that daily on these roads, vehicles carrying agricultural products toward the city of Oran. The geographical position of the Wilaya of Mascara axis between the north and south and east and west of Algeria supports the presence of the bus carrying passengers to the capital Algiers in particular via the N4 (Fig. 7). In addition, major construction works of the East-West Motorway and other penetrating favored the presence of heavy trucks carrying construction materials. The flat morphology of Sig and Mohammadia villages located on the axis N4 and poor quality of public transport has encouraged the use of both wheels of all kinds. This mode of transport is much responded particularly in these villages and is used as a means of transport by all categories of age.

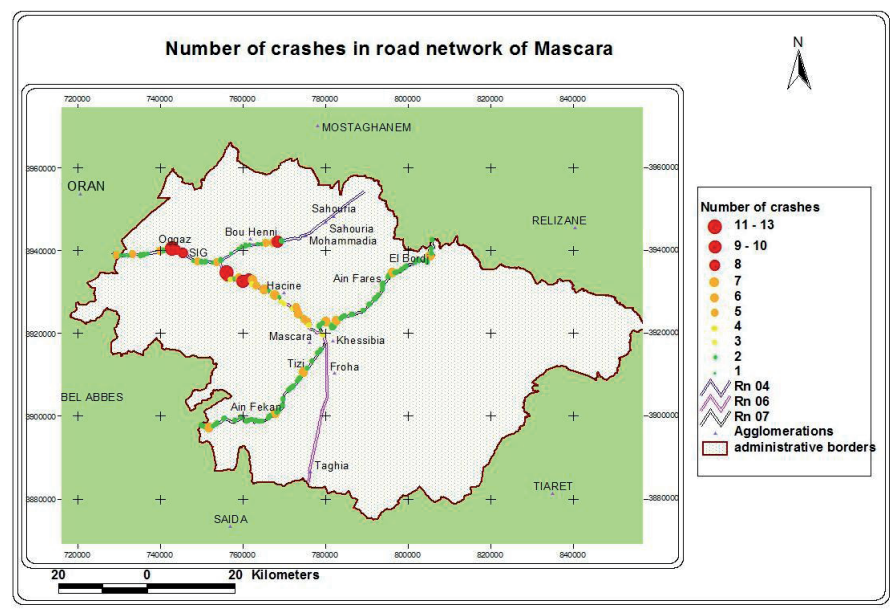

Fig. 7 Number of crashes in road network of Mascara

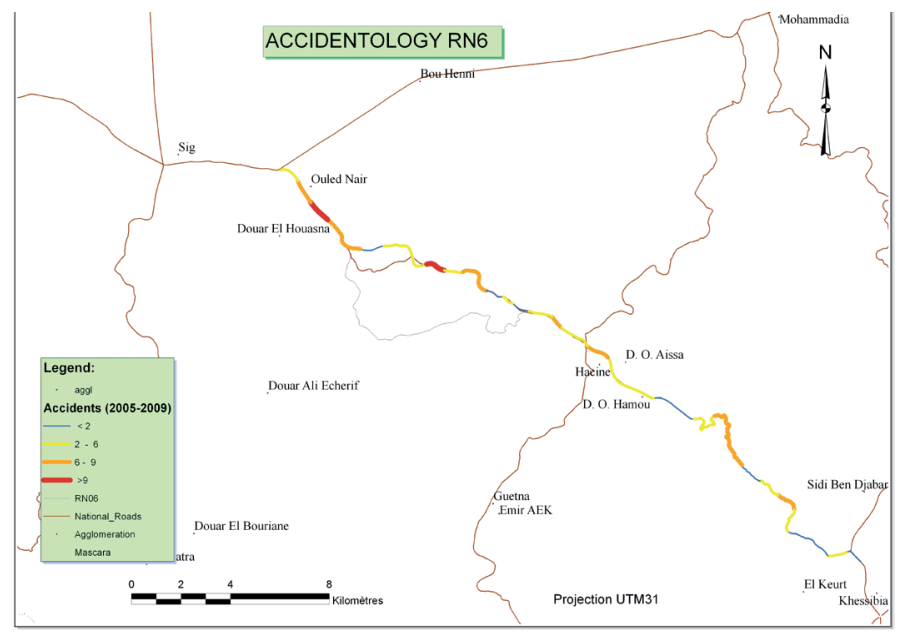

Fig. 8 Map of accident black areas on the section of RN6

This map shows the black areas of accidents on the N6 sections after segmented PK:

- The blue color represents the number of PK death of less than 2 killed as PK, 24 and 31, which are characterized by the presence of corners, so the driver is very careful and we have fewer fatalities and less killed;

- The yellow color for PK whose death toll is less than 6 killed;

- Orange PK for the death toll of less than nine killed.

- Red PK for which the death toll is more than 9 killed as PK2 with 17 killed and PK9 with 15 killed.

Based on the analysis of the question "specify the exact location of the accident," the majority of users involved in an accident are agreed on the danger of PK36, PK33, PK30 and PK5 including corners of the Hacine locality. 


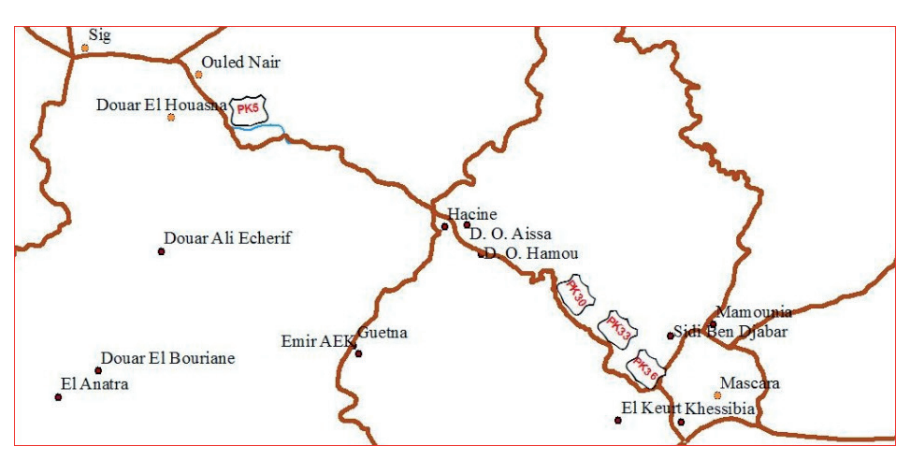

Fig. 9 Black areas locations according to users (survey)

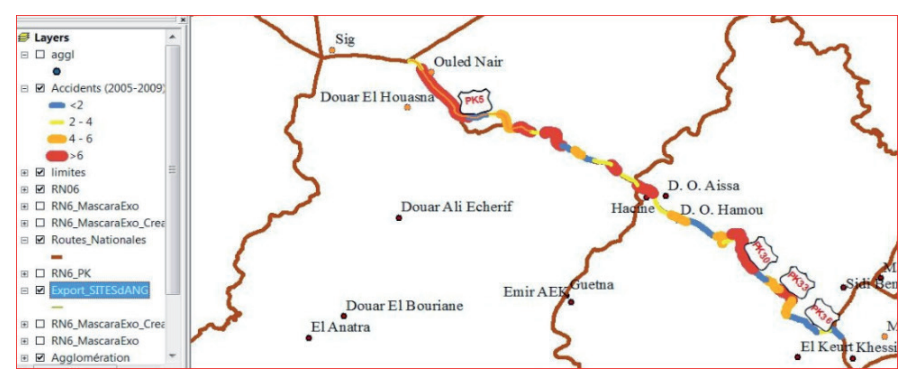

Fig. 10 Superimposition of the two card information

This map represents the juxtaposition between the GN data and data collected from users in terms of numbers killed by PK, the complementarities between the two sources has allowed us to develop a more comprehensive map.

\section{Conclusion}

The results of this study show that road users are daily witnesses to the degree of danger of their usual territory: the road. They can, therefore, be the source of information for locating high-risk areas on a daily basis through the road network. The causes of these accidents on this stretch are due to a multitude of factors which are they inter- related. These include human factors (driving experience, speeding, failure to respect the rules of the road, risk perception, etc.) and environmental factors (presence of bends, fittings unsuitable, weather conditions at the time of the accident, etc.) which are put forward in this paper.

This method can easily be used on other roads as it provides a precise look at local issues of road risk and certain adjustments unsuitable. The integration experiences of road users will undoubtedly improve safety on roads.

\section{Acknowledgement}

The project presented in this article is supported by the University of USTO-MB, University of Mascara, University Centre of Ain Temouchent and University of Sidi Bel Abbes in Algeria.

\section{References}

Anderson, T. (2007) comparison of spatial methods for measuring road accident 'hostpots': A case study of London. Journal of Maps. 3(1), pp. 55-63. DOI: 10.1080/jom.2007.9710827

Austin, K., Tight, M., Kirby, H. (1997) The use of geographical information systems to enhance road safety analysis. Transportation Planning and Technology. 20(3), pp. 249-266. DOI: 10.1080/03081069708717592
Çelik, K. A., Senger, Ö. (2014) Risk Factors Affecting Fatal Versus Non-Fatal Road Traffic Accidents: The Case Of Kars Province, Turkey. International Journal of Transport \& Traffic Engineering. 4(3), pp. 339-351. DOI: 10.7708/ijtte.2014.4(3).07

Chanut, O., Paché, G. (2011) Supply networks in urban logistics- Which strategies for 3PL?. In: EMNet Conference, Limassol, Cyprus, Dec 1-3, 2011.

Cloutier, M. S., Bergeron, J., Apparicio, P. (2011) Predictors of Parental Risk Perceptions: The Case of Child Pedestrian Injuries in School Context. Risk Analysis. 31(2), pp. 312-323. DOI: 10.1111/j.1539-6924.2010.01501.x

CNPSR. (2012). The National Center for Prevention and Road Safety. [Online]. Available from: www.cnpsr.org [Accessed: 15th December 2012]

Duffey, R. B., Saull, J. W. (2003) Know the Risk. Learning from Errors and Accidents: Safety and Risk in Today's Technology. Butterworth-Heinemann, Burlington, Mass.

Henri, P. (1995) Les SIG. Mise en æuvre et applications. (GIS, Implementation and Applications). 1st Edition, HERMES. (in French)

Joerin, F. (1997) Décider sur le territoire, proposition d'une approche par utilisation de SIG et de méthode d'analyse multicritère. (Decide On The Territory, Proposal An Approach Using Gis And Multi-Criteria Analysis Method.) p. 269. Thèse ${ }^{\circ} 1755$ présentée au département de génie rural, École Polytechnique Fédérale de Lausanne. (in French)

Lam, L. T. (2004) Environmental factors associated with crash-related mortality and injury among taxi drivers in New South Wales, Australia. Accident Analysis \& Prevention. 36(5), pp. 905-908.

DOI: 10.1016/j.aap.2003.10.001

Levulytė, L., Baranyai, D., Török, Á., Sokolovskij, E. (2016) Bicycles’ Role in Road Accidents a Review of Literature. Transport and Telecommunication Journal. 17(2), pp. 122-127. DOI: 10.1515/ttj-2016-0011

Mitsakis, E., Stamos, I., Grau, M. J., Morfoulaki, M. (2015) Bus Drivers Risk Perception of Roadway Hazards. Periodica Polytechnica Transportation Engineering. 43(1), pp. 15-21. DOI: 10.3311/PPtr.7481

Oulha, R.,Brahimi K., Boumediene A., Dali F., Madouche M. A. (2013) GIS Contribution to Identify Accident Black Spots on National Highway: Case Study of Wilaya of Mascara (Algeria). International Journal of Chemical,Environmental \& Biological Sciences. 5(1), pp. 775-778.

Oulha, R. (2004) Les caractéristiques des accidents de la route en Algérie. (The characteristics of road accidents in Algeria.), University of Science and Technology USTO-MB. Research paper.p. 116. (in French)

Savena, A. (2011) Environmental and Road Traffic Safety, CRRI, GIS, as an aid to Identify accident patterns. [Online]. Available from: http://www. gisdevelopment.net. [Accessed: 27th October 2014]

Subba Rao, N. V., Durga Rani, K., Rao, S. R. K. (2010) Analysis of Road Accidents on National Highway-5: An Indian Scenario. International Journal of Civil Engineering Research. 1(1), pp. 45-54.

Thériault, M. (1996) L'intégration des études environnementales et des systèmes d'informations géographiques pour appuyer les décisions d'aménagement : un objet de recherche prometteur. (The integration of environmental studies and geographical information systems to support planning and development decisions: a promising area of research.) Revue de géographie de Lyon. 71(2), pp. 155-156. DOI: 10.3406/geoca.1996.4339 (in French)

Transport and Road Research Laboratory. (1991) Towards Safer Roads in Developing Countries. A Guide for Planners and Engineers. Crowthrone: Transport Road Research Laboratory

Török, Á. (2015). Case Study on the Relationship between Road Safety and Economy in Hungary. American Journal of Vehicle Design. 3(1), pp. 1-5. DOI: 10.12691/ajvd-3-1-1

Zhao, Y., Zhang, J., He, X. (2015) Risk Factors Contributing to Taxi Involved Crashes: A Case Study in Xi'an, China. Periodica Polytechnica Transportation Engineering. 43(4), pp. 189-198. 2015. DOI: 10.3311/PPtr.7742 